Copyright (C) 2021 University of Bucharest Printed in Romania. All rights reserved ISSN print: $1224-5984$

ISSN online: $2248-3942$
Rom Biotechnol Lett. 2021; 26(3): 2650-2663

doi: $10.25083 / \mathrm{rbl} / 26.3 / 2650.2663$

Received for publication, December, 30, 2019

Accepted, December, 21, 2020

Original paper

\title{
The effect of production conditions on gene expression levels of inulinase of Aspergillus wentii NRLL 1778
}

\author{
AYTEN BOSTANCI ${ }^{1}$, FÍLIZ SANAL ${ }^{2 *}$ \\ ${ }^{1}$ University of Trakya, Department of Genetics and Bioengineering, Edirne, Turkey \\ ${ }^{2}$ University of Trakya, Faculty of Science, Department of Biology, Division of Molecular \\ Biology Edirne, Turkey
}

\begin{abstract}
In this study, the production of inulinase from Aspergillus wentii, the optimum conditions of that production and how those conditions influence gene expression levels of the enzyme were examined. For inulinase of $A$. wentii, the time of production was determined as 3 days, the temperature of production as $30^{\circ} \mathrm{C}$, the starting $\mathrm{pH}$ of the production medium as 6.0, and concentration of Jerusalem artichoke added in to production medium as $3 \%$. When the effect of $\mathrm{C}$ and $\mathrm{N}$ resources added to growth mediums on inulinase activity was investigated, the highest activity was observed in the medium containing $1 \%$ maltose. The medium containing $1 \%\left(\mathrm{NH}_{4}\right)_{2} \mathrm{HPO}_{4}$ was determined to be best growth medium. The enzyme was observed to be stable at $\mathrm{pH}$ 5.0-6.0 and to maintain its activity at $50^{\circ} \mathrm{C}$ for 30 minutes. It was found that gene expression was maximum at $2 \%$ Jerusalem artichoke concentration, $\mathrm{pH} 6.0,35^{\circ} \mathrm{C}$ on the $1^{\text {st }}$ day of production. The enzyme gene expression levels were higher compared to other studied resources when $1 \%$ cellulose was used as the carbon resource and $1 \% \mathrm{NH}_{4} \mathrm{H}_{2} \mathrm{PO}_{4}$ as the nitrogen resource.
\end{abstract}

Keywords Aspergillus wentii, inulinase, production, inulinase gene expression, thin layer chromatography (TLC).

To cite this article: BOSTANCI A, SANAL F. The effect of production conditions on gene expression levels of inulinase of Aspergillus wentii NRLL 1778. Rom Biotechnol Lett. 2021; 26(3): 2650.2663. DOI: $10.25083 / \mathrm{rbl} / 26.3 / 2650.2663$

*Corresponding author: FILIZ SANAL, Trakya University, Faculty of Sciences, Department of Biology, 22030 Edirne, Turkey

E-mail: filizsanal@trakya.edu.tr 


\section{Introduction}

Researches of biotechnology on industrial enzymes have become important because of gradually developing enzyme technology, diversity of products' usage areas, and their considerably high economic values (GESSESSE, 1998) [14]. High fructose syrups are essential, both to the food and drink industry as a low calorie sweetener and to the pharmacological industry as an additive (KANGO \& JAIN, 2011 [21]; SHARMA \& al, 2006 [37]). Fructose syrup has been relatively cost-effective, is produced easily and continuously, has a sucrose-like sweetness, has a better solubility and lower calorie count than glucose, and is widely used in both medical and various industrial applications. The importance of these syrups is why many companies are interested in easier production at a lower cost.

Inulinases are hydrolyses which yield fructose and glucose by targeting $\beta-(2,1)$ bonds of inulin (SHARMA \& al, 2006 [37]). Even though inulinases were first isolated from plants, it is difficult to isolate a sufficient amount of inulinase from plant tissues, making the process inadequate for commercial production. Therefore, interest in inulinases derived from microbes such as yeast, bacteria, and filamentous fungi has increased as the need to produce fructose grows (KUMAR \& al, 2005 [24]). Inulin is a linear polymer terminating with a D-glucose unit at reductive end, consisting of fructofuranose molecules that are linked with $\beta$ - $(2,1)$ glyosidic bonds (CHEN \& al, 2013 [4]). Because resources like inulin are relatively cheaper for microbial production of fructose syrup, they attract considerable interest. Microbial and herbal inulinases hydrolyze inulin into fructose or other oligosaccharides (AŞAN ÖZÜSAĞLAM, 2009 [2]).

Because production of fructose syrups by microbial resources is advantageous, in this study $A$. wentii was used as resource of inulinase. We examined how cultivation conditions of $A$. wentii influence inulinase activity and gene expression levels. This study is the first to examine how $A$. wentii growing conditions affect inulinase gene expression levels. We studied certain biochemical properties of the enzyme after optimization of production conditions had been ensured. Real time PCR analysis was used as a rapid and reliable method for determining expression levels of inulinase genes. We looked at the enzyme's mode of action via TLC analysis in order to determine whether $A$. wentii could be a potential inulinase producer on an industrial scale.

\section{Materials and Methods}

In this study, an A. wentii NRLL 1778 strain provided from the Department of Biology at Trakya University was used. Stock cultures were obtained through cultivation at $25^{\circ} \mathrm{C}$ for 5-7 days in a medium containing Jerusalem artichoke as the single carbon resource and were preserved at $4^{\circ} \mathrm{C}$ to use in further experiments. Stock cultures were refreshed by passaging monthly. A screening medium of Derycke and Wandamme (1984) was modified using Jerusalem artichoke instead of inulin and used for determining inulinase production of $A$. wentii (DERYCKE \& VANDAMME, 1984 [8]).

\section{Cultivation medium of $\boldsymbol{A}$. wentii}

Nutrient broths containing $1 \%$ Jerusalem artichoke powder, $0.05 \% \mathrm{MgSO}_{4} .7 \mathrm{H}_{2} \mathrm{O}, 0.15 \%$ yeast extract, $0.1 \%$ $\mathrm{KH}_{2} \mathrm{PO}_{4}, 0.092 \% \quad \mathrm{NH}_{4} \mathrm{NO}_{3}$, and $0.05 \% \mathrm{NH}_{4} \mathrm{H}_{2} \mathrm{PO}_{4}$ were used as culture mediums. Media were sterilized in an autoclave at $115^{\circ} \mathrm{C}$ for 30 minutes. $50 \mathrm{ml}$ of sterile culture media were prepared in $250 \mathrm{ml}$ Erlenmeyer flasks. A sum of strain from stocked cultures was taken in to physiological saline solution, $1 \mathrm{ml}$ of solution was inoculated each of $50 \mathrm{ml}$ culture medium. Inoculated media were left for growth in water baths that have $100 \mathrm{rpm}$ of shaking speed with different variables as regards to changing experimental conditions. Mycelia grown in our inulinase medium were removed filtering with the help of blotting paper after growth. Dry weights of mycelia were calculated drying in a petri dish along with blotting paper within oven at $80^{\circ} \mathrm{C}$ for 1 day. Filtrate was used as crude enzyme resource.

\section{Measurement of inulinase activity}

Inulinase activity was measured by incubating $1 / 20$ diluted $0.1 \mathrm{ml}$ enzyme and $1 \mathrm{ml}$ of $0.1 \%$ inulin solution (in a $0.1 \mathrm{M} \mathrm{pH} 5.0$ sodium acetate buffer) at $35^{\circ} \mathrm{C}$ for $10 \mathrm{~min}$ within a water bath. The reaction was stopped by adding 3,5-dinitrosalicylic acid (DNS) into the tubes at the end of incubation period. The tubes were boiled for 10 minutes. After they cooled, the optical density was measured in a spectrophotometer at $550 \mathrm{~nm}$ wave length. Blank and control reaction tubes were prepared as follow:

- Blank tubes $1 \mathrm{ml}$ Sodium - asetat buffer (pH:5), $3 \mathrm{ml}$ DNS

- Control tubes $1 \mathrm{ml} \mathrm{0.1 \%} \mathrm{inulin,} 3 \mathrm{ml}$ DNS

- Reaction tubes $1 \mathrm{ml} 0.1 \%$ inulin, $0.1 \mathrm{ml}$ enzyme, $3 \mathrm{ml}$ DNS

Activity of inulinase was measured by dinitrosalicylic acid (DNS) method using fructose as a standard. One unit of enzyme activity was defined as the quantity of enzyme to liberate $1 \mu \mathrm{mol}$ of fructose equivalent per minute at $35^{\circ} \mathrm{C}$ (SANAL et al, 2005 [36]).

\section{Effects of cultuvation time and temperature, initial pH of cultivation medium, carbon and nitrogen sources on inulinase production}

The $\mathrm{pH}$ of the production medium prepared as $50 \mathrm{ml}$ in $250 \mathrm{ml}$ Erlenmayer flasks was adjusted to 4, 5, 6, 7. 250 $\mathrm{ml}$ Erlenmayer flasks containing $50 \mathrm{ml}$ medium $(\mathrm{pH}$ 6) were used to change the production temperature $(25,30,35$ and $\left.40^{\circ} \mathrm{C}\right)$ and the production time $\left(1^{\text {st }}\right.$ day, $2^{\text {nd }}$ day, $3^{\text {rd }}$ day, $4^{\text {th }}$ days). While investigating the effect of carbon sources, $50 \mathrm{ml}$ of medium without carbon source was prepared in $250 \mathrm{ml}$ Erlenmayer flasks and different carbon sources such as inulin, maltose, cellulose, starch glucose, sucrose, pectin, jerusalem artichoke were added as the only carbon source at $1 \%$ final concentration. For its effect on enzyme production, organic and inorganic nitrogen sources $\left(\mathrm{NaNO}_{3}, \mathrm{NH}_{4} \mathrm{NO}_{3}, \mathrm{NH}_{4} \mathrm{H}_{2} \mathrm{PO}_{4},\left(\mathrm{NH}_{4}\right){ }_{2} \mathrm{HPO}_{4}, \mathrm{NH}_{4} \mathrm{Cl}\right.$, Cazein, Peptone, Yeast extract) were added to the cultivation medium at $1 \%$ final concentration. 


\section{RNA isolation, cDNA synthesis, and Real-Time PCR for gene expression Isolation of RNA}

For RNA isolation, specimens of $A$. wentii grown in nutrient broth were preserved at $-80^{\circ} \mathrm{C}$ with the addition of absolute ethanol until they were analyzed. Cells were lysed with CTAB and proteinase $\mathrm{K}$ for RNA isolation. Diethyl pyrocarbonate (DEPC) and Guanidium- $\mathrm{HCl}$ were used for deactivation of RNase, while silica columns were used for diffracting RNA and protein molecules. Contamination of DNA was eliminated by applying DNase.

The acid guanidinium thiocyanate-phenol-chloroform extraction method was used for RNA isolation (CHOMCZYNSKI \& SACCHI, 1987 [6]). A $500 \mu \mathrm{l}$ specimen was mixed with a $500 \mu \mathrm{l}$ denaturation solution (4 M guanidinium thiocyanate, $25 \mathrm{mM}$ sodium citrate, $\mathrm{pH} 7,0.5 \%$ sarcosyl, 0.1 M 2-mercaptoethanol) and incubated at room temperature for 5 minutes. $150 \mu \mathrm{l}$ of chloroform was added. It was shaken by hand for 15 seconds and incubated at room temperature for 3 minutes. The specimen was centrifuged at $12000 \mathrm{~g}, 4^{\circ} \mathrm{C}$ for 15 minutes before the supernatant was transferred to a fresh tube. $400 \mu 12$-propanol was added and incubated at room temperature for 10 minutes. After centrifuging at $12000 \mathrm{~g}, 4^{\circ} \mathrm{C}$, for 10 minutes, the supernatant was removed and $1 \mathrm{ml}$ of $75 \%$ ethanol was added and mixed. The specimen was centrifuged again at $7500 \mathrm{~g}, 4^{\circ} \mathrm{C}$ for 5 minutes. The supernatant was removed and the remaining ethanol was evaporated over 10 minutes.

At the final stage of isolation, RNAs adsorbing to silica columns were dissolved in water free from RNase/ Pyrogen. The amount of isolated nucleic acid and purity of the obtained RNA were determined using spectrophotometric analysis. Consequently, pellets of obtained RNA were dissolved in $50 \mu \mathrm{l}$ of deionized water without RNase and preserved at $-80^{\circ} \mathrm{C}$.

\section{Reverse Transcription}

$12 \mu \mathrm{l}$ RNA and $4 \mu \mathrm{l}$ oligo dT primer were mixed, incubated at $70^{\circ} \mathrm{C}$ for 10 minutes and then set in ice for 5 minutes. An $8 \mu 15 x$ reaction buffer $(250 \mathrm{mM}$ Tris-HC1 $\mathrm{pH} 8.3,375 \mathrm{mM} \mathrm{KCl}, 15 \mathrm{mM} \mathrm{MgCl} 2$ and $50 \mathrm{mM}$ DTT), $2 \mu \mathrm{ldNTP} \operatorname{mix}(40 \mathrm{mM}), 2 \mu \mathrm{l}$ reverse transcriptase $(200 \mathrm{U} / \mu \mathrm{l})$ and $28 \mu \mathrm{l}$ sterile deionized water were added, incubated at $37^{\circ} \mathrm{C}$ for 60 minutes and then at $60^{\circ} \mathrm{C}$ for 10 minutes. The obtained cDNA was stored at $-20^{\circ} \mathrm{C}$.

Within the established cDNA pool, the relative amount of cDNAs encoding inulinase enzyme compared to cDNAs encoding actin protein was determined using the Quantitative Real Time PCR (Q-PCR) and delta delta threshold cycle $\left(\mathrm{ddC}_{\mathrm{T}}\right)$ method.

\section{Quantitative Real Time PCR (Q-PCR)}

In this study, a BioSpeedy ${ }^{\mathrm{TM}}$ Aspergillus spp. Inulinase Relative Gene Expression Q-PCR Detection Kit (Bioeksen, Turkey) was used for Q-PCR. The kit includes forward 5'-GAG GTK TTT GGS GGR CAA GG-3' and reverse 5'-CC GCA CST CCA CCG AC-3' primers targeting the 123 base pair (bp) location of the Aspergillus spp. inulinase gene and forward 5'-TCT CCG ACC GTA TGC AGA AGG A-3' and reverse 5'-CTT CAT AGA CGA GGG AGC AAG GG-3' primers targeting the $53 \mathrm{bp}$ location of the actin gene. A Roche LightCycler® Nano device (Roche Diagnostics GmbH, Germany) was used to perform reactions. The reactions included $1.5 \mathrm{mM} \mathrm{MgCl}_{2}$, $0.2 \mathrm{mM}$ dNTP mix, 1x Reaction Buffer, 0.1 U Proof Reading Hot-Start Taq DNA Polimerase, 1x SybrGreen-I, $5 \mathrm{ng} / \mu \mathrm{l}$ template cDNA and $0.5 \mu \mathrm{M}$ from each primer. A replication reaction was performed as 1 cycle at $95^{\circ} \mathrm{C}$ for $10 \mathrm{~min}, 45$ cycles for $20 \mathrm{sec}$ at $95^{\circ} \mathrm{C}, 20 \mathrm{sec}$ at $55^{\circ} \mathrm{C}$, and $25 \mathrm{sec}$ at $72^{\circ} \mathrm{C}$. A melting curve analysis was performed between $55^{\circ} \mathrm{C}-95^{\circ} \mathrm{C}$ in order to determine if only the desired product was replicated during Q-PCR. The specific melting temperature $(\mathrm{Tm})$ expected for actin was $78-79^{\circ} \mathrm{C}$. For all template cDNAs, template RNAs synthesized by cDNA were used as negative controls to show that replication in the Q-PCR reactions originated from cDNA rather than contamination of DNA.

The Q-PCR data was analyzed using Roche Light Cycler NanoSoftware 1.0. One of the template DNAs was serially diluted and the yield of reaction was calculated. The yield of reaction varied from 1/9-2.0 and the obtained correlation factor $\left(r^{2}\right)$ was continuously above 0.97 . The relative expression level of inulinase to actin gene was calculated via the $2^{-\Delta \Delta C t}$ method (LIVAK \& SCHMITTGEN, 2001 [25], CHOMCZYNSKI \& SACCHI, 1987 [6]).

\section{Determination of Hydrolysis Products}

The hydrolysis products of inulin by crude enzyme were analyzed via TLC using silicagel plates (Merck, TLC aluminum plates, $20 \times 20 \mathrm{~cm}$, Silica gel $60 \mathrm{~F}_{254}$ ) (ERTAN \& EKINCI, 2002 [11]). $1.0 \mathrm{ml}$ of enzyme was incubated with $1.0 \mathrm{ml}$ of $1 \%$ inulin solution (in a $0.1 \mathrm{M} \mathrm{pH} 5.0$ acetate buffer) for $15 \mathrm{~min}, 30 \mathrm{~min}$, and $60 \mathrm{~min}$ at room temperature. The reaction was stopped by simmering tubes in a boiling water bath for 10 minutes. A standard consisting of $3 \mu 1$ of the specimen and $3 \mu \mathrm{l}$ of $1 \%$ inulin, fructose, glucose, and sucrose was applied to silica gel plates. An acetic acid: chloroform: water $(35: 30: 5 ; \mathrm{v} / \mathrm{v} / \mathrm{v})$ mixture was used as mobile phase. Air-dried plates were stained with an anilinediphenylamine agent, prepared by mixing 1 gr diphenylamine, $1 \mathrm{ml}$ aniline, and $10 \mathrm{ml}$ of $85 \%$ phosphoric acid with $100 \mathrm{ml}$ acetone. The final component was added to the mixture just before using. This agent was sprayed on to plates and visualization of spots occurred after heating at $120^{\circ} \mathrm{C}$ for 15 minutes. In this procedure, fructose and fructooligomers were seen as brown spots, glucose as blue spot, and sucrose as dark green spot. The colors remained visible for 6 hours (Fig. 7). Any products that became apparent on dried plates were photographed.

\section{Results and Discussion}

To determine the optimization of production time, media ( $\mathrm{pH}$ 6.0) were left to grow for 1-4 days within a shaking water bath $(100 \mathrm{rpm})$ at $25^{\circ} \mathrm{C}$. For the following studies, the time of production was determined to be 3 days. Maximum inulinase activity was measured as 1,385 $\mathrm{U} / \mathrm{ml}$ on the $3^{\text {rd }}$ day of growth. The weight of the mycelia was observed to increase until the $3^{\text {rd }}$ day, then decreased (Figure 1). The expression level of inulinase enzyme relative to actin was found to be at the maximum level on the $1^{\text {st }}$ day of production. 


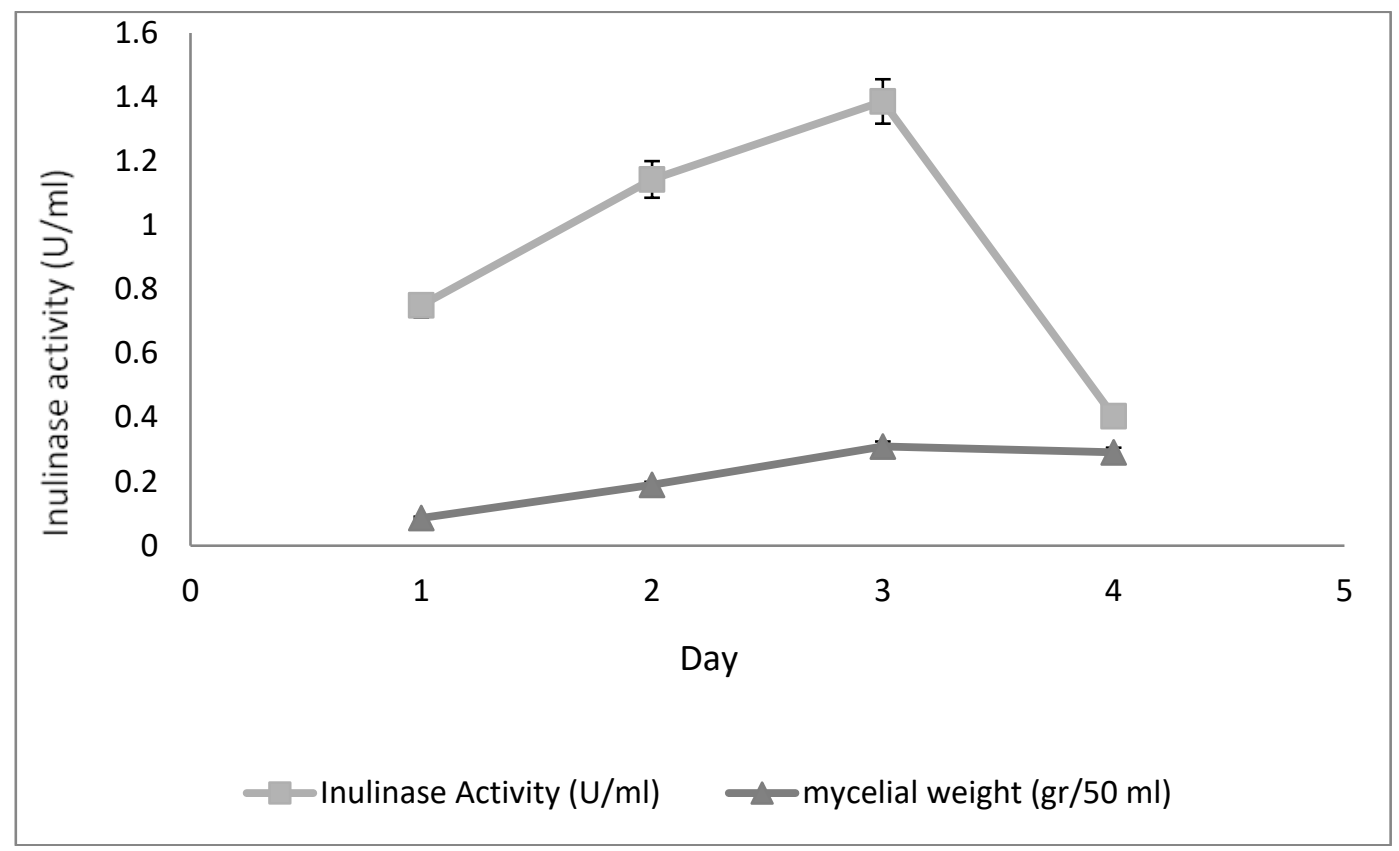

Figure 1. The effect of production time on inulinase activity. Data represent the mean of three replicates.

Inulinase activity and mycelia weight were measured by removing nutrient broths that were adjusted at $\mathrm{pH} 6.0$ and left within shaking water baths $(100 \mathrm{rpm})$ with different temperatures $\left(25,30,35\right.$, and $\left.40^{\circ} \mathrm{C}\right)$ at the end of the 3-day period. Highest enzyme activity was determined as $8.8 \mathrm{U} / \mathrm{ml}$ at $30^{\circ} \mathrm{C}$ (Figure 2$)$.

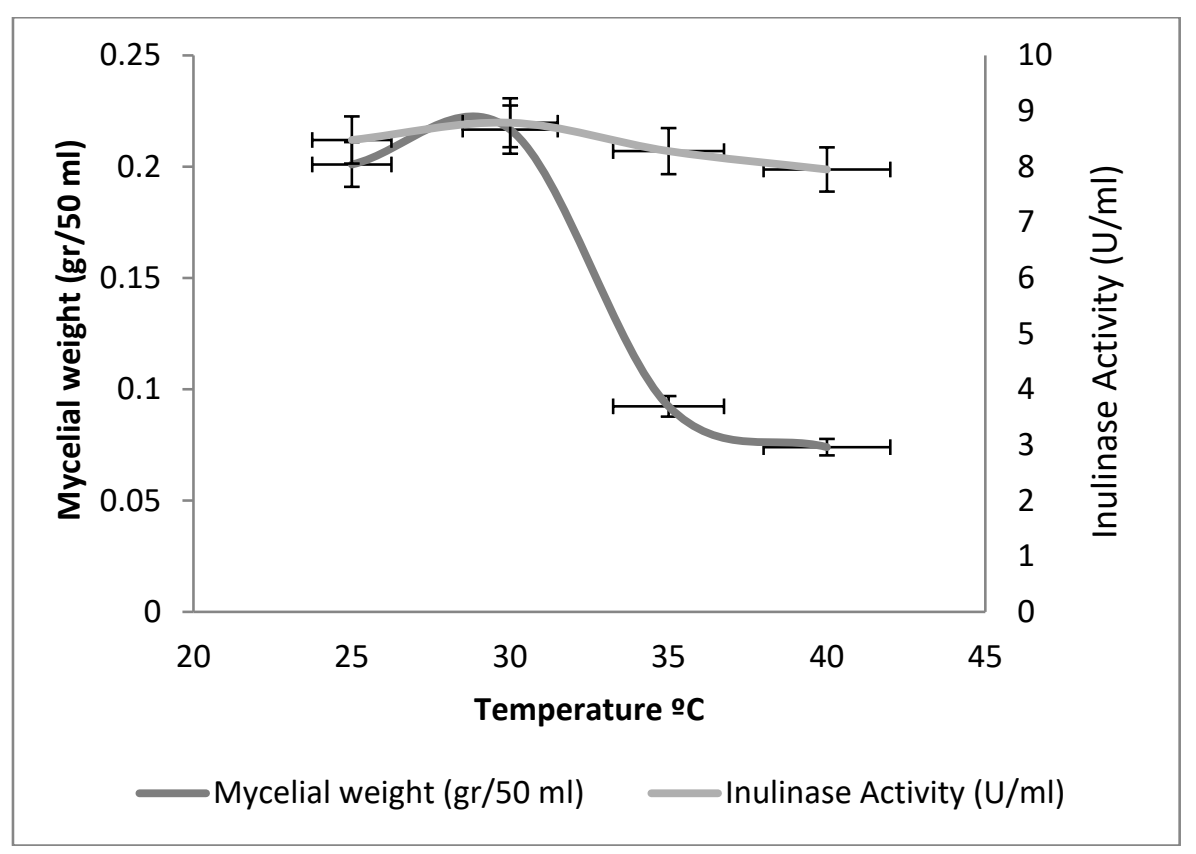

Figure 2. The effect of growth temperature on inulinase activity. Data represent the mean of three replicates.

The expression level of the inulinase enzyme relative to actin was detected from specimens obtained from the growth medium with the temperature of $35^{\circ} \mathrm{C}$.

A. wentii was grown within nutrient broths prepared at different $\mathrm{pHs}(4.0,5.0,6.0,7.0)$ in a shaking water bath
$(100 \mathrm{rpm})$ at $30^{\circ} \mathrm{C}$. Inulinase activity and mycelia weight were measured at the end of the 3-day period. Maximum activity was determined as $7.18 \mathrm{U} / \mathrm{ml}$ within the growth medium with 6.0 as the starting $\mathrm{pH}$ (Figure 3). 


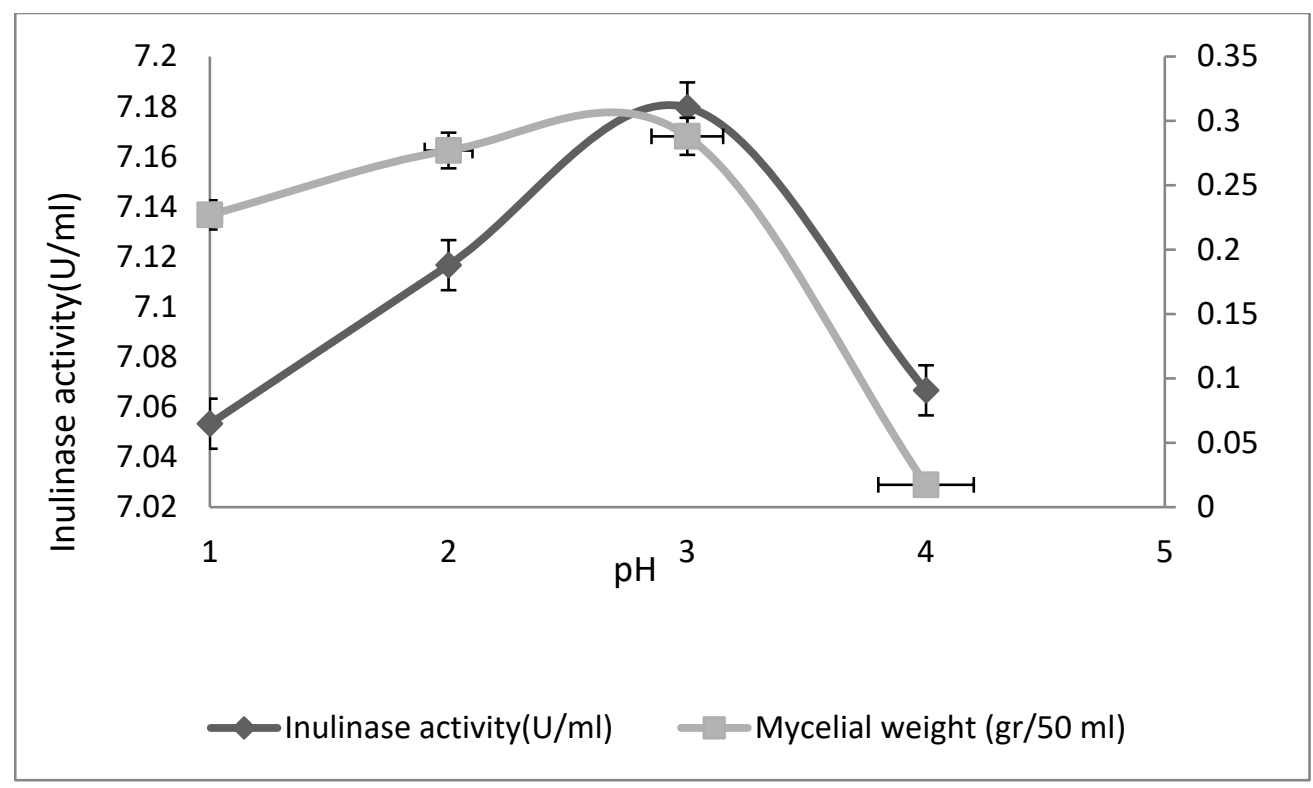

Figure 3. Effect of initial $\mathrm{pH}$ of the cultivation medium on inulinase production.

Data represent the mean of three replicates.

PCR results and biochemical results were parallel and the maximum gene expression level was determined in the growth medium with $\mathrm{pH} 6.0$.

The effect of the Jerusalem artichoke concentration on production of inulinase was determined by changing its percentage in $1 \%, 2 \%, 3 \%$, and $4 \%$ ratios. Maximum inulinase activity was measured as $8.74 \mathrm{U} / \mathrm{ml}$ in the nutrient broth with a $3 \%$ Jerusalem artichoke concentration. Activity was observed to decrease after $3 \%$ concentration. Mycelia weight was measured at the end period and the maximum mycelia weight was also found in the $3 \%$ Jerusalem artichoke concentration (Figure 4).

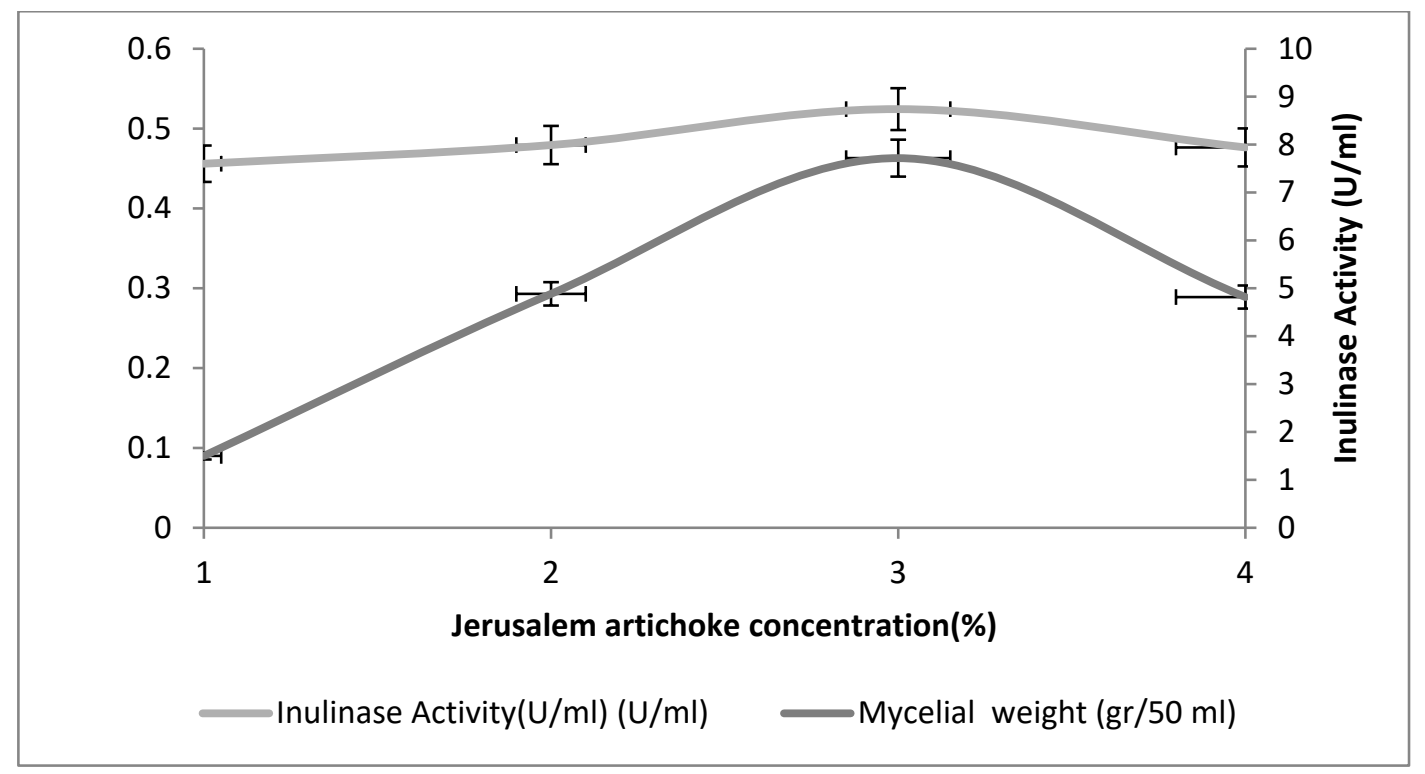

Figure 4. The effect of Jerusalem artichoke concentration added in to growth media on inulinase activity. Data represent the mean of three replicates.

The maximum expression of inulinase enzyme relative to actin was found in the $2 \%$ Jerusalem artichoke concentration (Table 1).

Nutrient broths prepared with different carbon resources were left for growth under determined optimum conditions. Maximum activity was found within the medium containing maltose $(8.38 \mathrm{U} / \mathrm{ml})$. The next-highest maximum activity was found in the medium containing sucrose $(8.01 \mathrm{U} / \mathrm{ml})$ and the third in the medium containing glucose $(7.99 \mathrm{U} / \mathrm{ml})$. On the gene expression level, maximum expression was observed to occur within the medium containing cellulose (Table 2). 
Table 1. The effect of Jerusalem artichoke concentration in growth medium on inulinase activity and gene expression. Data represent the mean of three replicates.

\begin{tabular}{|c|c|c|c|}
$\begin{array}{c}\text { Jerusalem } \\
\text { artichocke }\end{array}$ & $\begin{array}{c}\text { Inulinase } \\
\text { Activity (U/ml) }\end{array}$ & $\begin{array}{c}\text { Mycelial weight } \\
\text { (gr/50 ml) }\end{array}$ & $\begin{array}{c}\text { Relative Expression } \\
\text { Level of Inulinase to } \\
\text { Actin }\end{array}$ \\
\cline { 2 - 2 } $\mathbf{1}$ & $7,60 \pm 0,068$ & $0,090 \pm 0,005$ & $0,82 \pm 0,013$ \\
\hline $\mathbf{2}$ & $7,99 \pm 0,031$ & $0,293 \pm 0,026$ & $324,93 \pm 2,98$ \\
\hline $\mathbf{3}$ & $8,74 \pm 0,017$ & $0,463 \pm 0,0029$ & $50,61 \pm 0,33$ \\
\hline $\mathbf{4}$ & $7,94 \pm 0,014$ & $0,289 \pm 0,002$ & $4.12 \pm 0,064$ \\
\hline
\end{tabular}

Table 2. The effect of carbon resources in growth medium on inulinase activity and gene expression. Data represent the mean of three replicates.

\begin{tabular}{|c|c|c|c|}
\hline $\begin{array}{c}\text { Carbon } \\
\text { Source }(1 \%)\end{array}$ & $\begin{array}{l}\text { Inulinase } \\
\text { Activity } \\
\text { (U/ml) }\end{array}$ & $\begin{array}{l}\text { Mycelial weight } \\
\quad(\text { gr/50 ml })\end{array}$ & $\begin{array}{c}\text { Relative } \\
\text { Expression Level } \\
\text { of Inulinase to } \\
\text { Actin } \\
\end{array}$ \\
\hline Inulin & $7,86 \pm 0,081$ & $0,010 \pm 0,006$ & $0,15 \pm 0,002$ \\
\hline Maltose & $8,38 \pm 0,023$ & $0,022 \pm 0,001$ & $0,18 \pm 0,005$ \\
\hline Selulose & $7,34 \pm 0,054$ & $0,367 \pm 1,940$ & $356,97 \pm 1,94$ \\
\hline Starch & $7,60 \pm 0,016$ & $0,005 \pm 0,0005$ & $0,03 \pm 0,001$ \\
\hline Glucose & $7,99 \pm 0,083$ & $0,105 \pm 0,0015$ & $1,38 \pm 0,011$ \\
\hline Sucrose & $8,01 \pm 0,020$ & $0,172 \pm 0,0022$ & $0,18 \pm 0,003$ \\
\hline Pectin & $7,41 \pm 0,015$ & $0,058 \pm 0,0008$ & $0,57 \pm 0,013$ \\
\hline Jerusalem artichocke & $7,60 \pm 0,029$ & $0,090 \pm 0,0004$ & $0,82 \pm 0,015$ \\
\hline
\end{tabular}

Maximum activity was determined in the growth medium containing $\left(\mathrm{NH}_{4}\right)_{2} \mathrm{HPO}_{4}$ when nutrient broths prepared with different nitrogen resources was left for growth in determined optimum conditions and activity was measured at the end of the incubation period $(8.64 \mathrm{U} / \mathrm{ml})$.
The next-highest maximum activity was found in the medium containing yeast extract $(8.51 \mathrm{U} / \mathrm{ml})$ and next in the medium containing $\mathrm{NH}_{4} \mathrm{H}_{2} \mathrm{PO}_{4}(8.48 \mathrm{U} / \mathrm{ml})$. However, when looking at gene expression, maximum value was found in the medium containing $\mathrm{NH}_{4} \mathrm{H}_{2} \mathrm{PO}_{4}$ (Table 3).

Table 3. The effect of nitrogen resources in growth medium on inulinase activity and gene expression. Data represent the mean of three replicates.

\begin{tabular}{|c|c|c|c|}
\hline $\begin{array}{c}\text { N Source } \\
(\mathbf{1 \% )}\end{array}$ & $\begin{array}{c}\text { Inulinase Activity } \\
(\mathrm{U} / \mathrm{ml})\end{array}$ & $\begin{array}{l}\text { Mycelial weight } \\
(\text { gr/50 ml })\end{array}$ & $\begin{array}{c}\text { Relative Expression } \\
\text { Level of Inulinase to } \\
\text { Actin }\end{array}$ \\
\hline $\mathrm{NaNO}_{3}$ & $7,91 \pm 0,020$ & $0,013 \pm 0,004$ & $0,40 \pm 0,02$ \\
\hline Peptone & $7,86 \pm 0,034$ & $0,044 \pm 0,002$ & $0,13 \pm 0,002$ \\
\hline $\mathrm{NH}_{4} \mathrm{H}_{2} \mathrm{PO}_{4}$ & $8,48 \pm 0,020$ & $0,0002 \pm 7,07-5$ & $127,41 \pm 0,27$ \\
\hline Cazein & $8,25 \pm 0,053$ & $0,103 \pm 0,029$ & $5,48 \pm 0,13$ \\
\hline$\left(\mathrm{NH}_{4}\right)_{2} \mathrm{HPO}_{4}$ & $8,64 \pm 0,320$ & $0,0001 \pm 0,002$ & $0,63 \pm 0,023$ \\
\hline Yeast extract & $8,51 \pm 0,096$ & $0,025 \pm 0,003$ & $0,56 \pm 0,022$ \\
\hline $\mathrm{NH}_{4} \mathrm{Cl}$ & $8,12 \pm 0,195$ & $0,025 \pm 0,0027$ & $0,01 \pm 0,003$ \\
\hline $\mathrm{NH}_{4} \mathrm{NO}_{3}$ & $8,17 \pm 0,090$ & $0,019 \pm 0,0025$ & $0,44 \pm 0,015$ \\
\hline
\end{tabular}

The relative activity of the inulinase enzyme at 3.0-8.0 $\mathrm{pH}$ intervals in a $0.1 \mathrm{M}$ sodium acetate buffer (pH 3.0-5.0) and a 0.1 M phosphate buffer (pH 6.0-7.0) and a $0.1 \mathrm{M}$ Borate buffer $(\mathrm{pH} 8.0)$ is presented in Figure 5. The crude enzyme extracts maintained their activity at a high level at pH intervals of 5.0-6.0. Enzyme activity started to decrease after $\mathrm{pH} 6.0$, and regressed about $40 \%$ within the $\mathrm{pH} 7.0-8.0$ range. When enzyme activity was measured following it was treated within buffers prepared at different $\mathrm{pH}$ levels for 30 minutes at $4{ }^{\circ} \mathrm{C}$ (Figure 5). 


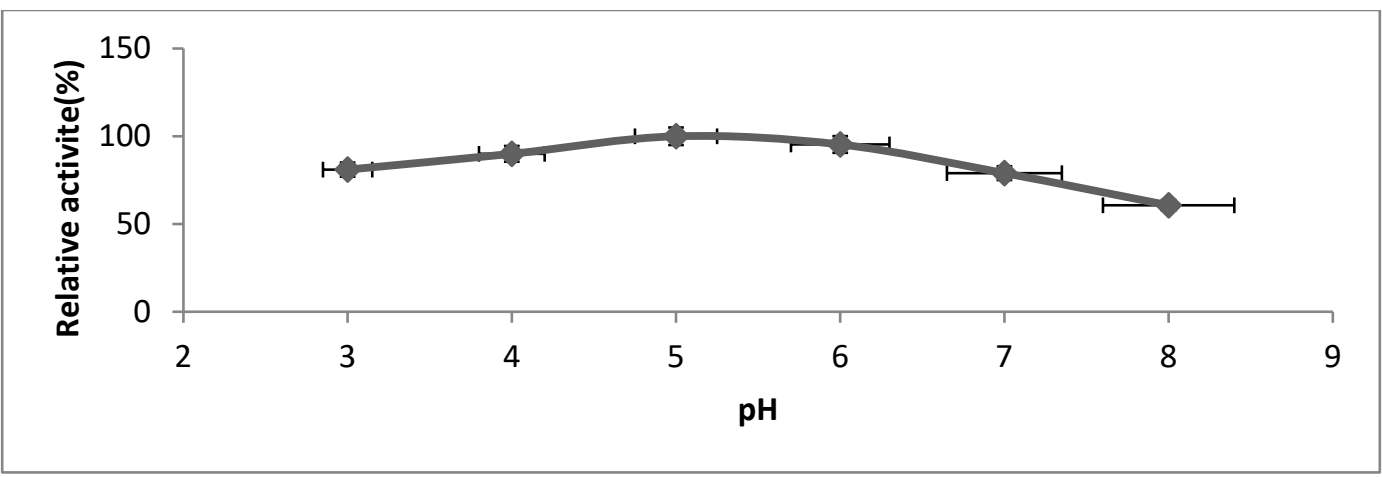

Figure 5. Effects of $\mathrm{pH}$ on enzyme stability. The studied $\mathrm{pH}$ range was 3.0-8.0 The results are expressed in terms of the residual activity of the inulinase extract. Data represent the mean of three replicates.

The inulinase enzyme maintained its activity at a high level $(87.5 \%)$ between $30-40^{\circ} \mathrm{C}$ and began to decrease and had a relative activity of $66.1 \%$ at $80^{\circ} \mathrm{C}$ (Figure 6).
Threshold Cycle Numbers $(\mathrm{Ct})$ and Melting Temperatures $(\mathrm{Tm})$ determined from actin gene targeted Q-PCR reactions were given in Table 4.

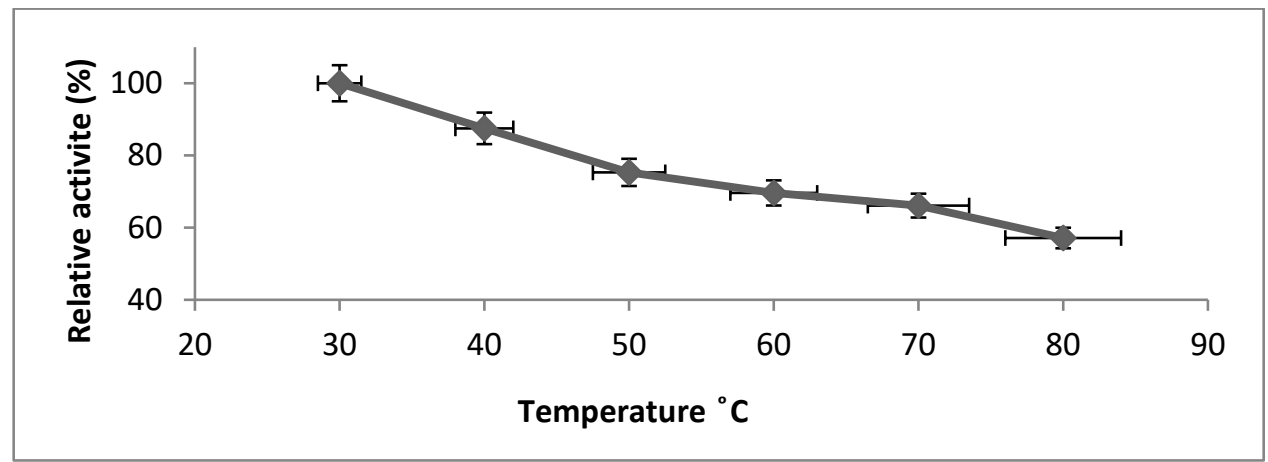

Figure 6. Thermal stability of inulinase enzyme. The studied temperature range was $30-80^{\circ} \mathrm{C}$. The results are expressed in terms of the residual activity of the inulinase extract. Data represent the mean of three replicates.

As it is seen in Table 4 replication was obtained from all Q-PCR reactions. As it is seen in Table 4 all of replications yield only actin gene specific Tm.

Threshold Cycle Numbers (Ct) and Melting Tempe- ratures $(\mathrm{Tm})$ determined from inulinase gene targeted Q-PCR reactions were given in Table 5. As it is seen in Table 5, replication was obtained from all Q-PCR reactions and all of replications yield only inulinase gene specific Tm.

Table 4. Threshold Cycle Numbers $(\mathrm{Ct})$ determined from actin gene targeted Q-PCR reactions and actin expression levels of specimens relative to one another, Melting Temperatures determined from Actin gene targeted Q-PCR reactions. Data represent the mean of three replicates.

\begin{tabular}{|c|c|c|c|c|}
\hline Sample & $\begin{array}{l}\text { Ct-Mean } \pm \text { STD } \\
\text { Deviation }\end{array}$ & $\begin{array}{l}\text { Relative } \\
\text { Number }\end{array}$ & $\begin{array}{l}\text { Relative Number } \\
\text { Std Deviation }\end{array}$ & $\begin{array}{c}\text { Tm-Mean } \pm \text { Std } \\
\text { Deviation }\end{array}$ \\
\hline $1^{\text {st }}$ day & $28.883 \pm 0.102$ & 67.446 & $1.46 \mathrm{E}-07$ & $78.52 \pm 0.08$ \\
\hline $2^{\text {nd }}$ day & $27.291 \pm 0.197$ & 203.375 & $1.42 \mathrm{E}-06$ & $78.51 \pm 0.04$ \\
\hline $3^{\text {th }}$ day & $28.889 \pm 0.328$ & 67.182 & $1.70 \mathrm{E}-07$ & $78.35 \pm 0.10$ \\
\hline $4^{\text {th }}$ day & $23.290 \pm 0.053$ & 3256.260 & $3.29 \mathrm{E}-04$ & $78.48 \pm 0.02$ \\
\hline $30^{\circ} \mathrm{C}$ & $27.186 \pm 0.549$ & 218.729 & $2.10 \mathrm{E}-06$ & $78.32 \pm 0.11$ \\
\hline $40^{\circ} \mathrm{C}$ & $32.803 \pm 0.571$ & 4.456 & $8.83 \mathrm{E}-10$ & $78.49 \pm 0.00$ \\
\hline $25^{\circ} \mathrm{C}$ & $25.384 \pm 0.618$ & 762.891 & $2.67 \mathrm{E}-05$ & $78.53 \pm 0.00$ \\
\hline $35^{\circ} \mathrm{C}$ & $34.959 \pm 2.973$ & 1.000 & $2.35 \mathrm{E}-10$ & $78.34 \pm 0.11$ \\
\hline pH 4.0 & $26.936 \pm 0.355$ & 260.054 & 2.59E-06 & $78.53 \pm 0.05$ \\
\hline pH 5.0 & $26.442 \pm 0.767$ & 366.330 & $6.84 \mathrm{E}-06$ & $78.56 \pm 0.02$ \\
\hline pH 6.0 & $31.693 \pm 0.882$ & 9.618 & $5.10 \mathrm{E}-09$ & $78.36 \pm 0.06$ \\
\hline pH 7.0 & $29.910 \pm 0.313$ & 33.098 & 4.07E-08 & $78.23 \pm 0.19$ \\
\hline $1 \%$ Jerusalem artichocke & $25.375 \pm 0.040$ & 767.310 & $1.81 \mathrm{E}-05$ & $78.38 \pm 0.06$ \\
\hline 2\% Jerusalem artichocke & $33.998 \pm 2.066$ & 1.947 & $4.75 \mathrm{E}-10$ & $78.34 \pm 0.13$ \\
\hline
\end{tabular}




\begin{tabular}{|c|c|c|c|c|}
\hline 3\% Jerusalem artichocke & $28.867 \pm 1.641$ & 68.230 & 4.35E-07 & $78.49 \pm 0.02$ \\
\hline 4\% Jerusalem artichocke & $28.455 \pm 0.852$ & 90.740 & $4.45 \mathrm{E}-07$ & $78.57 \pm 0.01$ \\
\hline Maltose & $23.213 \pm 0.140$ & 3435.569 & $3.89 \mathrm{E}-04$ & $78.64 \pm 0.03$ \\
\hline Pectin & $27.120 \pm 2.559$ & 229.021 & $9.26 \mathrm{E}-06$ & $78.41 \pm 0.05$ \\
\hline Sucrose & $24.228 \pm 1.411$ & 1699.624 & $2.30 \mathrm{E}-04$ & $78.57 \pm 0.05$ \\
\hline Starch & $21.152 \pm 1.221$ & 14335.785 & $1.43 \mathrm{E}-02$ & $78.61 \pm 0.00$ \\
\hline Cellulose & $32.756 \pm 1.342$ & 4.604 & $1.61 \mathrm{E}-09$ & $78.48 \pm 0.07$ \\
\hline Glucose & $26.166 \pm 0.713$ & 443.667 & $9.66 \mathrm{E}-06$ & $78.57 \pm 0.02$ \\
\hline Inulin & $23.027 \pm 0.167$ & 3908.321 & $5.14 \mathrm{E}-04$ & $78.61 \pm 0.03$ \\
\hline Peptone & $22.944 \pm 0.706$ & 4137.853 & 8.36E-04 & $78.57 \pm 0.01$ \\
\hline Yeast extract & $25.768 \pm 0.445$ & 584.611 & $1.39 \mathrm{E}-05$ & $78.55 \pm 0.03$ \\
\hline Casein & $28.651 \pm 0.450$ & 79.250 & $2.57 \mathrm{E}-07$ & $78.37 \pm 0.03$ \\
\hline $\mathrm{NH}_{4} \mathrm{H}_{2} \mathrm{PO}_{4}$ & $32.930 \pm 0.368$ & 4.081 & $6.44 \mathrm{E}-10$ & $78.44 \pm 0.03$ \\
\hline $\mathrm{NH}_{4} \mathrm{NO}_{3}$ & $29.206 \pm 0.756$ & 53.942 & $1.47 \mathrm{E}-07$ & $78.49 \pm 0.01$ \\
\hline $\mathrm{NH}_{4} \mathrm{Cl}$ & $28.675 \pm 1.771$ & 77.942 & $6.21 \mathrm{E}-07$ & $78.43 \pm 0.04$ \\
\hline $\mathrm{NaNO}_{3}$ & $31.792 \pm 0.798$ & 8.982 & 4.20E-09 & $78.42 \pm 0.02$ \\
\hline$\left(\mathrm{NH}_{4}\right)_{2} \mathrm{HPO}_{4}$ & $32.628 \pm 0.438$ & 5.033 & 1.03E-09 & $78.40 \pm 0.00$ \\
\hline
\end{tabular}

Table 5. Threshold Cycle Numbers $(\mathrm{Ct})$ determined from inulinase gene targeted Q-PCR reactions and inulinase expression levels of specimens relative to one another, Melting Temperatures determined from Inulinase gene targeted Q-PCR reactions. Data represent the mean of three replicates.

\begin{tabular}{|c|c|c|c|}
\hline Sample & $\begin{array}{c}\text { Ct-Mean } \pm \text { STD } \\
\text { Deviation }\end{array}$ & $\begin{array}{l}\text { Relative Number } \\
\text { Std Deviation }\end{array}$ & $\begin{array}{c}\text { Tm-Mean } \pm \text { Std } \\
\text { Deviation }\end{array}$ \\
\hline $1^{\text {st }}$ day & $6.38 \pm 0.11$ & $269.35 \pm 3.49$ & $82.535 \pm 0.133$ \\
\hline $2^{\text {nd }}$ day & $6.84 \pm 0.55$ & $195.32 \pm 2.49$ & $82.565 \pm 0.035$ \\
\hline $3^{\text {th }}$ day & $6.61 \pm 0.20$ & $228.33 \pm 2.67$ & $82.459 \pm 0.106$ \\
\hline $4^{\text {th }}$ day & $5.96 \pm 0.23$ & $358.71 \pm 6.74$ & $82.570 \pm 0.096$ \\
\hline $30^{\circ} \mathrm{C}$ & $4.52 \pm 0.07$ & $974.83 \pm 44.48$ & $82.313 \pm 0.012$ \\
\hline $40^{\circ} \mathrm{C}$ & $6.17 \pm 0.12$ & $310.91 \pm 4.70$ & $82.563 \pm 0.072$ \\
\hline $25^{\circ} \mathrm{C}$ & $4.87 \pm 1.47$ & $763.24 \pm 72.33$ & $82.612 \pm 0.066$ \\
\hline $35^{\circ} \mathrm{C}$ & $6.56 \pm 0.17$ & $237.59 \pm 2.84$ & $82.616 \pm 0.050$ \\
\hline pH 4.0 & $5.45 \pm 0.19$ & $511.05 \pm 13.30$ & $82.673 \pm 0.135$ \\
\hline pH 5.0 & $5.15 \pm 0.49$ & $628.02 \pm 24.73$ & $82.638 \pm 0.082$ \\
\hline pH 6.0 & $5.11 \pm 0.79$ & $649.42 \pm 32.52$ & $82.534 \pm 0.084$ \\
\hline pH7.0 & $5.56 \pm 0.52$ & $473.32 \pm 14.41$ & $82.502 \pm 0.082$ \\
\hline 1\% Jerusalem artichocke & $5.15 \pm 0.61$ & $630.49 \pm 27.19$ & $82.419 \pm 0.091$ \\
\hline $2 \%$ Jerusalem artichocke & $5.14 \pm 0.12$ & $632.53 \pm 19.38$ & $82.598 \pm 0.066$ \\
\hline 3\% Jerusalem artichocke & $2.70 \pm 0.21$ & $3453.08 \pm 615.14$ & $82.567 \pm 0.087$ \\
\hline 4\% Jerusalem artichocke & $5.90 \pm 0.26$ & $374.03 \pm 7.49$ & $82.639 \pm 0.109$ \\
\hline Maltose & $5.14 \pm 1.00$ & $634.29 \pm 36.01$ & $82.618 \pm 0.054$ \\
\hline Pectin & $7.42 \pm 0.31$ & $130.63 \pm 0.94$ & $82.697 \pm 0.170$ \\
\hline Sucrose & $6.20 \pm 0.08$ & $305.28 \pm 4.39$ & $82.655 \pm 0.074$ \\
\hline Starch & $5.74 \pm 0.73$ & $417.80 \pm 12.99$ & $82.484 \pm 0.077$ \\
\hline Celluose & $3.77 \pm 0.03$ & $1643.63 \pm 123.49$ & $82.682 \pm 0.071$ \\
\hline Glucose & $5.19 \pm 0.91$ & $613.39 \pm 31.52$ & $82.697 \pm 0.170$ \\
\hline Inulin & $5.25 \pm 0.48$ & $585.96 \pm 21.36$ & $82.624 \pm 0.027$ \\
\hline Peptone & $5.37 \pm 0.22$ & $542.57 \pm 15.37$ & $82.653 \pm 0.011$ \\
\hline Yeast extract & $6.10 \pm 0.15$ & $326.97 \pm 5.32$ & $82.685 \pm 0.088$ \\
\hline Casein & $5.69 \pm 0.05$ & $434.54 \pm 8.76$ & $82.531 \pm 0.010$ \\
\hline $\mathrm{NH}_{4} \mathrm{H}_{2} \mathrm{PO}_{4}$ & $5.43 \pm 0.38$ & $519.99 \pm 15.69$ & $82.441 \pm 0.061$ \\
\hline $\mathrm{NH}_{4} \mathrm{NO}_{3}$ & $9.87 \pm 0.63$ & $23.96 \pm 0.04$ & $82.484 \pm 0.049$ \\
\hline $\mathrm{NH}_{4} \mathrm{Cl}$ & $14.45 \pm 0.16$ & $1.00 \pm 0.00$ & $82.613 \pm 0.078$ \\
\hline $\mathrm{Na} \mathrm{NO}_{3}$ & $12.59 \pm 0.58$ & $3.62 \pm 0.00$ & $82.446 \pm 0.179$ \\
\hline$\left(\mathrm{NH}_{4}\right)_{2} \mathrm{HPO}_{4}$ & $12.79 \pm 0.04$ & $3.16 \pm 0.00$ & $82.272 \pm 0.143$ \\
\hline
\end{tabular}


Expression level of inulinase relative to actin gene was calculated via $2^{-\Delta \Delta \mathrm{Ct}}$ method described by Livak and
Schmittgen (2001). Results were given in Table 6 (LIVAK \& SCHMITTGEN, 2001).

Table 6. Expression level of inulinase relative to actin gene. Data represent the mean of three replicates.

\begin{tabular}{|c|c|c|c|}
\hline Numune & $\begin{array}{c}\text { Relative Expression } \\
\text { Level of Actin } \pm \\
\text { STD Deviation }\end{array}$ & $\begin{array}{l}\text { Relative Expression } \\
\text { Level of Inulinase }\end{array}$ & $\begin{array}{c}\text { Relative Expression } \\
\text { Level of Inulinase to } \\
\text { Actin }\end{array}$ \\
\hline $1^{\text {st }}$ day & $67,45 \pm 1,46$ & $269,35 \pm 2,46$ & $3,99 \pm 0,01$ \\
\hline $2^{\text {nd }}$ day & $203,38 \pm 1,55$ & $195,32 \pm 1,40$ & $0,96 \pm 0,015$ \\
\hline $3^{\text {th }}$ day & $67,18 \pm 1,20$ & $228,33 \pm 1,06$ & $3,40 \pm 0,057$ \\
\hline $4^{\text {th }}$ day & $3256,26 \pm 3,20$ & $358,71 \pm 2,32$ & $0,11 \pm 0,05$ \\
\hline $30^{\circ} \mathrm{C}$ & $218,73 \pm 2,12$ & $974,83 \pm 6,48$ & $4,46 \pm 0,015$ \\
\hline $40^{\circ} \mathrm{C}$ & $4,46 \pm 0,57$ & $310,91 \pm 1,45$ & $69,78 \pm 0,45$ \\
\hline $25^{\circ} \mathrm{C}$ & $762,89 \pm 2,48$ & $763,24 \pm 2,66$ & $1,0 \pm 0$ \\
\hline $35^{\circ} \mathrm{C}$ & $1,00 \pm 2,25$ & $237,59 \pm 2,49$ & $237,65 \pm 0,75$ \\
\hline pH 4.0 & $260,05 \pm 2,59$ & $511,05 \pm 4,86$ & $1,97 \pm 0,01$ \\
\hline pH 5.0 & $366,33 \pm 6,84$ & $628,02 \pm 11,46$ & $1,71 \pm 0,017$ \\
\hline pH 6.0 & $9,62 \pm 0,90$ & $649,42 \pm 9,71$ & $67,52 \pm 0,02$ \\
\hline pH 7.0 & $33,10 \pm 4,05$ & $473,32 \pm 1,46$ & $14,30 \pm 0,064$ \\
\hline $1 \%$ Jerusalem artichocke & $767,31 \pm 1,82$ & $630,49 \pm, 084$ & $0,82 \pm 0,01$ \\
\hline 2\% Jerusalem artichocke & $1,95 \pm 0,14$ & $632,53 \pm 0,96$ & $324,93 \pm 11,57$ \\
\hline 3\% Jerusalem artichocke & $68,23 \pm 4,35$ & $345,08 \pm 1,81$ & $50,61 \pm 0,20$ \\
\hline 4\% Jerusalem artichocke & $90,74 \pm 4,5$ & $374,03 \pm 3,85$ & $4,12 \pm 0,015$ \\
\hline Maltose & $3435,57 \pm 3,89$ & $634,29 \pm 2,16$ & $0,18 \pm 0,08$ \\
\hline Pectin & $229,02 \pm 2,12$ & $130,63 \pm 1,95$ & $0,57 \pm 0,005$ \\
\hline Sucrose & $1699,62 \pm 2,34$ & $305,28 \pm 4,87$ & $0,18 \pm 0,008$ \\
\hline Starch & $14335,79 \pm 1.45$ & $417,80 \pm 9,36$ & $0,03 \pm 0,003$ \\
\hline Cellulose & $4,60 \pm 1,61$ & $164,63 \pm 1,74$ & $356,97 \pm 0,119$ \\
\hline Glicose & $443,67 \pm 9,66$ & $613,39 \pm 1,46$ & $1,36 \pm 0,020$ \\
\hline Inulin & $3908,32 \pm 5,14$ & $585,96 \pm 5,85$ & $0,15 \pm 0,005$ \\
\hline Peptone & $4137,85 \pm 8,36$ & $542,57 \pm 1,38$ & $0,13 \pm 0,005$ \\
\hline Yeast extract & $584,61 \pm 1,38$ & $326,97 \pm 2.17$ & $0,56 \pm 0,01$ \\
\hline Casein & $79,25 \pm 2,56$ & $434,54 \pm 1,46$ & $5,48 \pm 0,015$ \\
\hline $\mathrm{NH}_{4} \mathrm{H}_{2} \mathrm{PO}_{4}$ & $4,08 \pm 0,26$ & $519,99 \pm 0,99$ & $127,41 \pm 0,106$ \\
\hline $\mathrm{NH}_{4} \mathrm{NO}_{3}$ & $53,94 \pm 1,47$ & $23,96 \pm 4,46$ & $0,44 \pm 0,01$ \\
\hline $\mathrm{NH}_{4} \mathrm{Cl}$ & $77,94 \pm 1,78$ & $1,00 \pm 0,01$ & $0,01 \pm 0,0015$ \\
\hline $\mathrm{Na} \mathrm{NO}_{3}$ & $8,98 \pm 0,78$ & $3,62 \pm 0,16$ & $0,40 \pm 0,015$ \\
\hline$\left(\mathrm{NH}_{4}\right)_{2} \mathrm{HPO}_{4}$ & $5,03 \pm 0,43$ & $3,16 \pm 0,6$ & $0,63 \pm 0,005$ \\
\hline
\end{tabular}

\section{Determination of Hydrolysis Products}

Using the procedure stated for TLC, fructose and fructose oligomers were occurred as brown spots, glucose as blue spots, and sucrose as green spots. It was observed that the product yielded as the result of enzyme reactions was fructose. TLC analysis of hydrolysis product of inulin observed that major product is fructose which suggested that the enzyme showed exotype hydrolysis activity. Accordingly, it can be explained that $A$. wentii inulinase is exoinulinase (Figure 7).

Because effect levels of microbial enzymes on their substrates are directly proportionate to the enzyme activity they produce under optimum growth conditions, conditions influencing the growth process of these microorganisms have been studied by numerous researchers (DAS et al, 2019, TAŞAR, 2020 [7, 44]). These studies are crucial in terms of advancing productive yields of enzymes.
This parameters were not researched with Aspergillus wentii NRLL 1778 so far. For these reasons, the effects of time, temperature, $\mathrm{pH}$, and the different carbon and nitrogen resources that influence the production of the inulinase enzyme by the Aspergillus wentii NRLL 1778 strain were researched. The characteristics of the enzyme, such as $\mathrm{pH}$ and thermal stability, which could support industrial use of the enzyme, were also examined.

When correlation between time of production and inulinase activity was investigated, maximum inulinase activity $1,385 \mathrm{U} / \mathrm{ml}$ was determined at the end of 3 days. Time of production was chosen as 3 days. Other studies also found that various species yielded their maximum activities for inulinase enzyme at the end of 72 hours, including Ertan and Ekinci 2002 for Alternaria alternata (ERTAN \& EKINCI, 2002 [11]), Souza-Motta \& al, 2005 for Aspergillus niveus 4128URM (SOUZA-MOTTA \& al, 2005 [43]), 


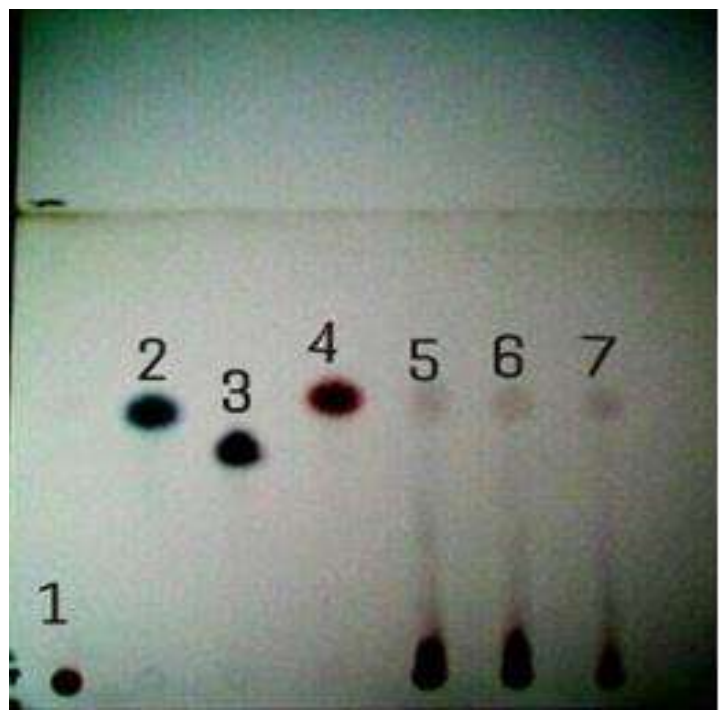

Figure 7. TLC profile of hydrolysis product of $A$. wentii inulinase: 1. Inulin (St); 2. Sucrose (St); 3. Glucose (St); 4. Fructose (St); 5. 15 min hydrolysis; 6. 30 min hydrolysis; 7. 60 min hydrolysis.

Kumar \& al, 2005 for Aspergillus niger AUP19 (KUMAR $\&$ al, 2005 [24]), Makino \& al, 2009 for Kluyveromyces marxianus NRRL Y-7571 (MAKINO \& al, 2009 [26]), Yepez \& al, 2005 for K. marxianus (YEPEZ \& al, 2005 [49]), Gao \& al, 2007 for such species as Pichia guilliermondii, Cryptococcus aureus, Debaryomyces hansenii, and Yarrowia lipolytica (GAO \& al, 2007 [13]). The time detected by these researchers is similar to our finding.

Besides this, fairly different times of production were reported by various researchers about Aspergillus for production of inulinase enzyme (KANGO \& JAIN, 2011 [21]; GUPTA \& al, 1994b [19]). Johnson \& al (1968) in their study conducted with $A$. wentii, found a production time of 5-7 days (JOHNSON \& al, 1968 [20]). Ertan \& al (2002) determined the time when A. parasiticum shows optimum activity as 24 hours (ERTAN \& EKINCI, 2002 [11]), Öngen-Baysal \& al (1994) found 8 days for $A$. niger AU2 (ÖNGEN-BAYSAL \& al, 1994 [32]), Chen \& al (2009) as 5 days for A. ficuum JN SP5-06 (CHEN \& al, 2009 [3]), Viswanathan \& Kulkarni (1995) found maximum activity time of $A$. niger van Tieghem as 60 hours (VISWANATHAN \& KULKARNI, 1995 [47]). Gupta et al (1994) detected maximum inulinase activity on the $9^{\text {th }}$ day in their study conducted with several Aspergillus species such as A. aureus, A. fischeri, A. flavus, A. nidulans, and A. niger (GUPTA \& al, 1994a [17]).

In our study, a correlation between the temperature of the growth medium and inulinase activity revealed maximum activity with $8.8 \mathrm{U} / \mathrm{ml}$ occurred at $30^{\circ} \mathrm{C}$. Generally, the production temperature of inulinase produced by fungi is reported to fall between $28-30^{\circ} \mathrm{C}$ (KANGO \& JAIN, 2011 [21]).

Johnson \& al (1968) determined production temperature as $28^{\circ} \mathrm{C}$ in their study carried out on $A$. wentii (JOHNSON \& al, 1968 [20]), Ertan \& Ekinci (2002) determined production time of fungus at $30^{\circ} \mathrm{C}$ in their study on Alternaria alternate and at $25^{\circ} \mathrm{C}$ in their study conducted with A. niger and Trichoderma harzianum (ERTAN \& EKINCI, 2002 [11]). Nakamura \& al (1997) found the production temperature of Penicillium spp. TN-88 strain as $30^{\circ} \mathrm{C}$; (NAKAMURA et al, 1997 [30]) Gupta et al (1990) found the production temperature of Fusarium oxysporum as $25^{\circ} \mathrm{C}$ (GUPTA \& al, 1990 [18]) and Ertan \& al (2003) found production temperature of Rhizoctonia solani as $28^{\circ} \mathrm{C}$ (ERTAN \& al, 2003 [10]).

When correlation between the initial $\mathrm{pH}$ of production media and inulinase activity was viewed, maximum inulinase activity $(7.18 \mathrm{U} / \mathrm{ml})$ was found in the growth medium with $\mathrm{pH}$ 6.0. In studies by Warchol \& al, 2002 (WARCHOL \& al, 2002 [47]) carried out with Bifidobacterium infantis ATCC 15697 and by Ertan and Ekinci 2002 (ERTAN \& EKINCI, 2002 [11]) with A. alternata, maximum activity was found at the same level, $\mathrm{pH}$ 6.0. The optimum $\mathrm{pH}$ value was also stated as 6.0 for $A$. niger SL 09, Trichoderma harzianum, and $K$. marxianus ATCC 52466 strains (KANGO \& JAIN, 2011 [21]; ERTAN \& EKINCI, 2002 [11]; PANDEY \& al, 1999a [33]). However optimum $\mathrm{pH}$ values for the production medium preferred by species producing inulinase is between considerably wide interval form acidic $\mathrm{pH}$ values to basic $\mathrm{pH}$ values. It has been reported that the optimum $\mathrm{pH}$ values of fungal and yeast purified inulinases vary from 4.5 to 6.0 (GONG \& al, 2007 [15]; SHENG \& al, 2008 [38]; PANDEY \& al, 1999a [33]; PANDEY \& al, 1999b [34]; ZHANG \& al, 2005 [51]; SINGH \& al, 2007 [41]).

When the correlation of different carbon sources and inulinase activity was examined, it was found that maximum activity with $8.38 \mathrm{U} / \mathrm{ml}$ appeared in the medium containing $1 \%$ maltose as a single carbon source. The medium containing $1 \%$ sucrose produced the next highest level, with $8.01 \mathrm{U} / \mathrm{ml}$ inulinase activity. $7.99 \mathrm{U} / \mathrm{ml}$ inulinase activity was observed within the medium containing 
$1 \%$ glucose. It was observed that activity in starch, Jerusalem artichoke, pectin and cellulose used in place of inulin produced lower levels of activity.

In many studies, changes in inulinase activity were observed by adding different carbon sources to the production medium. Kumar \& al (2005) used inulin and galactose, Skowronek and Fiedurek (2004) used sucrose, Park and Yun (2001) dandelion roots, Singh et al (2007b) tubers of asparagus as resource of carbon (KANGO \& JAIN, 2011 [21]). It has been observed that the carbon sources that researchers have preferred most in their experiments are natural sources of inulin and sucrose.

When we examined mycelia weights in different carbon resources, maximum mycelia weight was seen in medium containing $1 \%$ cellulose. But inulinase activity is minimum level. However, even though inulinase activity was high, mycelia weight was quite low in medium containing maltose.

According to data obtained from our study, Jerusalem artichoke concentration was determined to be important in terms of enzyme activity. While inulinase activity obtained from $1 \%$ Jerusalem artichoke concentration was the same as produced within medium containing starch, inulinase activity obtained from medium with $3 \%$ Jerusalem artichoke concentration was determined higher than $1 \%$ maltose containing medium which had maximum activity observed. This makes us thought that concentration could also be a factor influencing production of inulinase as much as type of carbon resource.

Examining the correlation between inulinase activity and different nitrogen resources added to the medium determined that maximum inulinase activity $(8.64 \mathrm{U} / \mathrm{ml})$ was found in the medium containing $1 \%\left(\mathrm{NH}_{4}\right)_{2} \mathrm{HPO}_{4}$ as the nitrogen resource. Among the other sources of nitrogen added to the medium, inulinase activity was low in production media containing casein, $\mathrm{NH}_{4} \mathrm{NO}_{3}, \mathrm{NH}_{4} \mathrm{Cl}, \mathrm{NaNO}_{3}$ and peptone. When the mycelium weights were evaluated, a minimum mycelium weight $(0.0001 \mathrm{gr} / 50 \mathrm{ml})$ was found when maximum activity was obtained on the medium using $\left(\mathrm{NH}_{4}\right)_{2} \mathrm{HPO}_{4}$ as the nitrogen source. The maximum amount of mycelium was found to be $0.13(\mathrm{gr} / 50 \mathrm{ml})$ in the casein-used medium.

Nitrogen sources most preferred by researchers in experiments were yeast extract, $(\mathrm{NH} 4)_{2} \mathrm{HPO}_{4}$ and $\mathrm{NH}_{4} \mathrm{NO}_{3}$. Many different plant species such as corn syrup (KUMAR \& al, 2005 [24]) soybean (NAIDOO \& al, 2009 [29]) Asparagus officinalis (SINGH \& BHERMI, 2008 [40]) and $\mathrm{NH}_{4} \mathrm{H}_{2} \mathrm{PO}_{4}$, (TREICHEL \& al, 2009 [45]) yeast extract, corn steep liquor (CSL) (MAZUTTI \& al, 2010 [27]) have been used in many studies as a nitrogen source.

In industrial inulin hydrolysis, temperatures of $60^{\circ} \mathrm{C}$ and higher are used in order to minimize the risk of contamination and to increase solubility. Enzymes with high thermostability are industrially suitable for ensuring appropriate solubility of inulin at high temperatures, simultaneously preventing microbial contamination, producing desired product with lower amounts of enzyme, and decreasing costs of production (VANDAMME \& DERYCKE, 1983 [46]; ALLAIS \& al, 1987 [1], DRENT \& al, 1991
[9]). However, inulinase enzymes obtained from yeast, fungi, and bacteria were not always able to maintain their activity levels at the high temperatures required for industrial applications (SINGH \& GILL, 2006 [39]).

In our study, $A$. wenti inulinase maintained $46.4 \%$ of its activity at $80^{\circ} \mathrm{C}$. This observation leads us to believe it should be considered an enzyme which might be utilized industrially. Previous studies also indicate certain enzymes can function at high temperatures, although the stability times and ratios of the enzyme vary according to the species of fungus and bacteria. M.K Kim \& al, 1994 isolated a thermostable inulinase enzyme from Scytalidium acidophilum and stated that its activity at $60^{\circ} \mathrm{C}$ after 6 hours of incubation was about $95 \%$, falling to $85 \%$ at $65^{\circ} \mathrm{C}$ (KIM $\&$ al, 1994 [23]). A. ficuum inulinase enzyme was incubated at $60^{\circ} \mathrm{C}$ and $70^{\circ} \mathrm{C}$ for 6 hours and determined to have $74 \%$ and $22 \%$ activity respectively (ETTALIBI \& BARATTI, 1990 [12]). In another study, the thermal stability of Aspegillus oryzae inulinase was investigated and the enzyme was found to maintain $90 \%$ of its activity at $70^{\circ} \mathrm{C}$ (GUPTA \& al, 1998 [16]). Further strengthens our work which there are not many examples of inulinases from fungi that can maintain their activity at such high temperatures.

In terms of $\mathrm{pH}$ stability, it was observed that $A$. wentii inulinase maintained $95 \%$ of its activity between the 5.0$6.0 \mathrm{pH}$ range. Activity decreased after $\mathrm{pH}$ 6.0, and had residual activity of $61 \%$ at $\mathrm{pH} 8.0$. It has been reported that when Pichia guilliermondii inulinase is incubated at $\mathrm{pH} 4.0-9.0$ for 2 hours, the enzyme maintains $95 \%$ of its activity at $\mathrm{pH}$ 6.0-7.0 and significantly decreases its activity after pH 7.0 (SINGH \& GILL, 2006 [39]; ZHANG $\&$ al, 2009 [50]). Further reinforcing our study, Chi \& al, 2009 states that $\mathrm{pH}$ stability of soil-derived fungi and yeasts is generally 4.0-8.0 (CHI \& al, 2009 [5]).

A TLC analysis of reaction products was performed in order to determine whether the hydrolysis of crude inulinase was of the exo or endo type. The fact that fructose was the major sugar produced during hydrolysis indicated that $A$. wentii inulinase hydrolyzed inulin via an exo type reaction. This is the first report on the production of an exoinulinase from Aspergillus wentii. Exoinulinases play a major role in the analysis of natural inulin fructose to prepare high-fructose syrup, which is used in many applications such as dairy products and candies in the food industry. Thus, a thermostable inulinolytic enzyme would be expected to play an important role in food and chemical industries in which fructose syrup is widely applied.

A. alternata, A. niger (ERTAN \& EKINCI, 2002 [11]), Penicillium sp. Strain TN-88 (MORIYAMA \& al, 2002 [28]) Aspergillus awomori (PANDEY \& al, 1999b [34]), Thermotoga maritima (ROBERFROID \& al, 1998 [35]) were reported as exo type inulinase producers. T. harzianum (ERTAN \& EKINCI, 2002 [11]), Penicillium purpurugenum (ONODERA \& al, 1996 [31]), Aspergillus niger 20 OSM strain (SKOWRONEK \& FIEDUREK, 2006 [42]), on the other hand, were reported as fungi producing endo inulinase.

A. wentii's growth conditions on gene expression levels relative to actin are not comparable, one-to-one, with 
biochemical results. The measurement of inulinase activity in $\mathrm{U} / \mathrm{ml}$ ignores the physiological activity levels of an A. wentii cell found in $1 \mathrm{ml}$ broth except inulinase activity. Because overall activity of cells increased under these experimental conditions, the level of all proteins produced by cells could be increased. In other words, inulinase activity is understood to remain constant if the activity of a gene like actin, which increases-decreases in parallel to the physiological level of the cell, also increases $100 \%$ alongside the $100 \%$ increase of inulinase activity from $1 \mathrm{U} / \mathrm{ml}$ to $100 \mathrm{U} / \mathrm{ml}$.

When calculating relative gene expression, normalization is performed to proportion the inulinase level to the actin level. This is why a change in the inulinase/actin ratio is directly associated with a change in inulinase activity. In our study, the Jerusalem artichoke concentration was increased from $1 \%$ to $2 \%$, but there was no change for inulinase activity in $\mathrm{U} / \mathrm{ml}$. However, the change was reflected in the inulinase/actin ratio where we observed a nearly $400 \%$ activity increase.

As seen in Table 6, parameters that were thought to influence enzyme activity were examined via the $\mathrm{Ct}$ method, using gene expression levels obtained from mycelia produced at $25^{\circ} \mathrm{C}$ as the base, assuming 1.0. Gene expression was determined to be high, of gene expression levels relative to actin, on the $1^{\text {st }}$ day of production, when the temperature was $35^{\circ} \mathrm{C}$ and the starting $\mathrm{pH}$ value was 6.0. An evaluation was carried out as resources were added to the growth medium, which showed that gene expression levels were higher in media prepared using $2 \%$ Jerusalem artichoke and $1 \%\left(\mathrm{NH}_{4}\right)_{2} \mathrm{HPO}_{4}$ as compared to other resources. Experiments to determine the most suitable $\mathrm{pH}$ found that the biochemical data and gene expression levels were exactly equivalent in both outcomes, and that the study results were similar to the study temperature and the Jerusalem artichoke concentration, which were influenced by other variables studied. Studies on the effects of fungi production conditions on enzyme expression are notably limited. The only study on the inulinase enzyme is the quantitative expression analysis of the inulinase gene cluster of the Penicillium sp. TN-88 strain. In the study of the effects of $\mathrm{C}$ sources on the transcription levels of the Inu $\mathrm{C}$ and Inu D genes, the study was compared with the $\mathrm{Ct}$ method based on the gene expression level in the glucose-containing medium. They determined at the end of 72 hours of production that expression levels of Inu C and Inu D genes increased 42 and 3260 times, respectively, within a medium using inulin as single carbon resource. Moriyama and colleagues reported in this study that gene expression levels were suppressed by glucose and sucrose and this was associated with the fact that enzyme synthesis was subjected to catabolite repression (MORIYAMA \& al, 2002 [28]).

Molecular studies are instructive and supportive in terms of adapting biological substrates to technology in order to achieve maximum efficiency. In our research, findings were applied to $A$. wentii inulinase for the first time, indicating that how growth conditions of fungi affect the expression of enzymes might be a reference for future molecular studies. In our study, the results of our biochemical parameters and gene expression studies suggest that $A$. wentii inulinase has a high thermal stability, making it a suitable fungal source for industrial scale use. These findings support our findings in our earlier work. This study first assessed the effect of production conditions on the expression levels of the enzyme and supported previous findings (KARATOP R \& al, 2013 [22]).

\section{Conclusion}

In conclusion, this work presents the characteristics of crude inulinase preparation from A. wentii. The pattern of inulin hydrolysis by this enzyme, the relatively high thermal stability and high activity at slightly acidic $\mathrm{pH}$ makes it of potential importance in the production of fructose from inulin.

\section{Acknowledgments}

The corresponding author is grateful to Trakya University Foundation of Scientific Research. This was a part of study of Research Project numbered 2013-01 supported by Trakya University Foundation of Scientific Research.

Author's contributions: F. Sanal designed the transformation experiments and conducted initial trials and A. Bostanci conducted transformation experiments. A. Bostanci and F. Sanal wrote the manuscript and F. Sanal compiled molecular data and read the manuscript. F. Sanal critically analyzed the manuscript.

\section{Conflict of interest disclosure}

The authors declare no conflictof interest.

Note: This study is part of postgraduate thesis of Ayten Bostanci.

\section{References}

1. ALLAIS, J.-J., HOYOS-LOPEZ, G., KAMMOUN, S. \& BARATTI, J.C. Isolation and characterization of thermophilic bacterial strains with inulinase activity. Applied and Environmental Microbiology, 53, 942-945 (1987).

2. AŞAN ÖZÜSAĞLAM, M. İnulinaz Enziminin Önemi. Anadolu Üniversitesi Bilim ve Teknoloji Dergisi 10, 327-334 (2009).

3. CHEN, H.Q., CHEN, X.-M., LI, Y., WANG, J., JIN, Z.-Y., XU, X.-M., ZHAO, J.-W., CHEN, T.X. \& XIE, Z.J. Purification and characterisation of exo-and endoinulinase from Aspergillus ficuum JNSP5-06. Food Chemistry, 115, 1206-1212 (2009).

4. CHEN, X.M., XU, X.M., JIN, Z.Y. \& CHEN, H.Q. Expression of an exoinulinase gene from Aspergillus ficuum in Escherichia coli and its characterization. Carbohydrate p-Polymers, 92, 1984-1990 (2013).

5. CHI, Z., CHI, Z., ZHANG, T., LIU, G. \& YUE, L. Inulinase-expressing microorganisms and applications 
of inulinases. Applied Microbiology and Biotechnology, 82, 211-220 (2009).

6. CHOMCZYNSKI, P. \& SACCHI, N. Single-step method of RNA isolation by acid guanidinium thiocyanate-phenol-chloroform extraction. Analytical Biochemistry, 162, 156-159 (1987).

7. DAS, D., BHAT, R. \& SELVARAJ, R. Review of inulinase production using solid-state fermentation. Annals of Microbiology, 69, 201-209 (2019).

8. DERYCKE, D.G. \& VANDAMME, E.J. Production and properties of Aspergillus niger inulinase. Journal of Chemical Technology and Biotechnology. Biotechnology, 34, 45-51 (1984).

9. DRENT, W.J., LAHPOR, G.A., WIEGANT, W.M. \& GOTTSCHAL, J.C. Fermentation of inulin by Clostridium thermosuccinogenes sp. nov., a thermophilic anaerobic bacterium isolated from various habitats. Applied and Environmental Microbiology, 57, 455-462 (1991).

10. ERTAN, F., AKTAÇ, T., KABOGLU, A.Ç., EKINCI, F. \& BAKAR, E. Determination of optimum cultivation conditions on the production of inulinase from Rhizoctonia solani. Pakistan Journal of Biological Sciences, 6, 1386-1388 (2003).

11. ERTAN, F. \& EKINCI, F. The production of inulinase from Alternaria alternata, Aspergillus niger and Trichoderma harzianum, J. Marmara Pure Appl. Sci, 18, e15 (2002).

12. ETTALIBI, M. \& BARATTI, J.C. Molecular and kinetic properties of Aspergillus ficuum inulinases. Agricultural and biological chemistry, 54, 61-68 (1990).

13. GAO, L., CHI, Z., SHENG, J., WANG, L., LI, J. \& GONG, F. Inulinase-producing marine yeasts: evaluation of their diversity and inulin hydrolysis by their crude enzymes. Microbial Ecology, 54, 722-729 (2007).

14. GESSESSE, A. Purification and properties of two thermostable alkaline xylanases from an alkaliphilic Bacillus sp. Appl Environ Microbiol, 64, 3533-5 (1998).

15. GONG, F., SHENG, J., CHI, Z. \& LI, J. Inulinase production by a marine yeast Pichia guilliermondii and inulin hydrolysis by the crude inulinase. Journal of Industrial Microbiology \& Biotechnology, 34, 179-185 (2007).

16. GUPTA, A.K., GILL, A. \& KAUR, N. A $\mathrm{HgCl}_{2}$ insensitive and thermally stable inulinase from Aspergillus oryzae. Phytochemistry, 49, 55-58 (1998).

17. GUPTA, A.K., GILL, A., KAUR, N. \& SINGH, R. High thermal stability of inulinases from Aspergillus species. Biotechnology letters, 16, 733-734 (1994a).

18. GUPTA, A.K., SINGH, D.P., KAUR, N. \& SINGH, R. Production, purification and immobilisation of inulinase from Kluyveromyces fragilis. Journal of Chemical Technology and Biotechnology, 59, 377-385 (1994b).

19. JOHNSON, D., NELSON, G. \& CIEGLER, A. Starch hydrolysis by conidia of Aspergillus wentii. Applied Microbiology, 16, 1678-1683 (1968).
20. KANGO, N. \& JAIN, S.C. Production and properties of microbial inulinases: recent advances. Food Biotechnology, 25, 165-212(2011).

21. KARATOP R, SANAL. F.A potential resourcein fructose production from inulin: Aspergillus wentii 1nulinase 11(1\&2): 21-28. Journal of Cell and Molecular Biology, 11, 21-28 (2013).

22. KIM, M.K., KIM, Y.H., KIM, H.R., KIM, B.I., BYUN, S.M. \& UHM, T.B. Thermal stability of an acidic inulinase from Scytalidium acidophilum. Biotechnology Letters, 16, 965-966 (1994).

23. GUPTA, A.K., RATHORE, P., KAUR, N. \& SINGH, R. Production, thermal stability and immobilisation of inulinase from Fusarium oxysporum. Journal of Chemical Technology and Biotechnology, 47, 245-257 (1990).

24. KUMAR, G.P., KUNAMNENI, A., PRABHAKAR, T. \& ELLAIAH, P. Optimization of process parameters for the production of inulinase from a newly isolated Aspergillus niger AUP19. World Journal of Microbiology and Biotechnology, 21, 1359-1361 (2005).

25. LIVAK, K.J. \& SCHMITTGEN, T.D. Analysis of relative gene expression data using real-time quantitative PCR and the $2^{-\Delta \Delta C T}$ method. methods, 25, 402408 (2001).

26. MAKINO, Y., TREICHEL, H., MAZUTTI, M.A., MAUGERI, F. \& RODRIGUES, M.I. Inulinase bioproduction using agroindustrial residues: screening of microorganisms and process parameters optimization. Journal of Chemical Technology and Biotechnology, 84, 1056-1062 (2009).

27. MAZUTTI, M.A., ZABOT, G., BONI, G., SKOVRONSKI, A., DE OLIVEIRA, D., DI LUCCIO, M., RODRIGUES, M.I., TREICHEL, H. \& MAUGERI, F. Optimization of inulinase production by solid-state fermentation in a packed-bed bioreactor. Journal of Chemical Technology and Biotechnology, 85, 109-114 (2010).

28. MORIYAMA, S., AKIMOTO, H., SUETSUGU, N., KAWASAKI, S., NAKAMURA, T. \& OHTA, K. Purification and properties of an extracellular exoinulinase from Penicillium sp. strain TN-88 and sequence analysis of the encoding gene. Bioscience, Biotechnology, and Biochemistry, 66, 1887-1896(2002).

29. NAIDOO, K., AYYACHAMY, M., PERMAUL, K. \& SINGH, S. Enhanced fructooligosaccharides and inulinase production by a Xanthomonas campestris pv. phaseoli KM 24 mutant. Bioprocess and Biosystems Engineering, 32, 689-695 (2009).

30. NAKAMURA, T., SHITARA, A., MATSUDA, S., MATSUO, T., SUIKO, M. \& OHTA, K. Production, purification and properties of an endoinulinase of Penicillium sp. TN-88 that liberates inulotriose. Journal of Fermentation and Bioengineering, 84, 313-318 (1997).

31. ONODERA, S., MURAKAMI, T., ITO, H., MORI, H., MATSUI, H., HONMA, M., CHIBA, S. \& SHIOMI, N. 
Molecular cloning and nucleotide sequences of cDNA and gene encoding endo-inulinase from Penicillium purpurogenum. Bioscience, biotechnology, and biochemistry, 60, 1780-1785 (1996).

32. ÖNGEN-BAYSAL, G., SUKAN, Ş.S. \& VASSILEV, N. Production and properties of inulinase from Aspergillus niger. Biotechnology Letters, 16, 275-280 (1994).

33. PANDEY, A., SELVAKUMAR, P., SOCCOL, C.R. \& NIGAM, P. Solid state fermentation for the production of industrial enzymes. Current Science, 77, 149-162 (1999a).

34. PANDEY, A., SOCCOL, C.R., SELVAKUMAR, P., SOCCOL, V.T., KRIEGER, N. \& FONTANA, J.D. Recent developments in microbial inulinases. Applied Biochemistry and Biotechnology, 81, 35-52 (1999b).

35. ROBERFROID, M.B., VAN LOO, J.A. \& GIBSON, G.R. The bifidogenic nature of chicory inulin and its hydrolysis products. The Journal of Nutrition, 128, 11-19 (1998).

36. SANAL, F.E., ERTAN, F. \& AKTAC, T. Production of Exo-inulinase from Alternaria alternata growth on Jerusalem Artichoke and some biochemical properties. Journal of Biological Sciences, 5, 497-505 (2005).

37. SHARMA, A.D., KAINTH, S. \& GILL, P.K. Inulinase production using garlic (Allium sativum) powder as a potential substrate in Streptomyces sp. Journal of Food Engineering, 77, 486-491 (2006).

38. SHENG, J., CHI, Z., GONG, F. \& LI, J. Purification and characterization of extracellular inulinase from a marine yeast Cryptococcus aureus G7a and inulin hydrolysis by the purified inulinase. Applied Biochemistry and Biotechnology, 144, 111-121 (2008).

39. SINGH, P. \& GILL, P.K. Production of inulinases: recent advances. Food Technology and Biotechnology, 44, 151-162 (2006).

40. SINGH, R. \& BHERMI, H. Production of extracellular exoinulinase from Kluyveromyces marxianus YS-1 using root tubers of Asparagus officinalis. Bioresource Technology, 99, 7418-7423 (2008).

41. SINGH, R.S., DHALIWAL, R. \& PURI, M. Partial purification and characterization of exoinulinase from Kluyveromyces marxianus YS-1 for preparation of high-fructose syrup. Journal of Microbiology and Biotechnology, 17, 733-738 (2007).
42. SKOWRONEK, M. \& FIEDUREK, J. Purification and Properties of Extracellular Endoinulinase from Aspergillus niger 20 OSM. Food Technology \& Biotechnology, 44 (2006).

43. SOUZA-MOTTA, C.M.D., CAVALCANTI, M.A.D.Q., PORTO, A.L.F., MOREIRA, K.A. \& LIMA FILHO, J.L.D. Aspergillus niveus Blochwitz 4128URM: New source for inulinase production. Brazilian Archives of Biology and Technology, 48, 343-350 (2005).

44. TAŞAR, Ö.C. Inulinase Production Capability of a Promising Medicinal Plant: Inula viscosa. Kommagene Biyoloji Dergisi, 4, 19-20 (2020).

45. TREICHEL, H., MAZUTTI, M.A., MAUGERI, F. \& RODRIGUES, M.I. Use of a sequential strategy of experimental design to optimize the inulinase production in a batch bioreactor. Journal of Industrial Microbiology \& Biotechnology, 36, 895-900 (2009).

46. VANDAMME, E.J. \& DERYCKE, D.G. Microbial inulinases: fermentation process, properties and applications. Adv. Appl. Microbiol, 29, e176 (1983).

47. VISWANATHAN, P. \& KULKARNI, P. Properties and application of inulinase obtained by fermentation of costus (Saussurea lappa) root powder with Aspergillus niger. Food/Nahrung, 39, 288-294 (1995).

48. WARCHOL, M., PERRIN, S., GRILL, J.P. \& SCHNEIDER, F. Characterization of a purified $\beta$-fructofuranosidase from Bifidobacterium infantis ATCC 15697. Letters in Applied Microbiology, 35, 462-467 (2002).

49. YEPEZ, S., BERNARDO, O. \& MAUGERI, F. Kluyveromyces marxianus physiology on several levels of carbon, nitrogen sources and oxygenation during inulinase production. In: JOURNAL OF BIOTECHNOLOGY, ELSEVIER SCIENCE BV PO BOX 211, 1000 AE AMSTERDAM, NETHERLANDS, S44-S44 (2005).

50. ZHANG, L., ZHAO, C., OHTA, W.Y. \& WANG, Y. Inhibition of glucose on an exoinulinase from Kluyveromyces marxianus expressed in Pichia pastoris. Process Biochemistry, 40, 1541-1545 (2005).

51. ZHANG, T., GONG, F., PENG, Y. \& CHI, Z. Optimization for high-level expression of the Pichia guilliermondii recombinant inulinase in Pichia pastoris and characterization of the recombinant inulinase. Process Biochemistry, 44, 1335-1339 (2009). 